\title{
Diagnóstico florístico-estrutural do componente arbóreo da floresta da Serra de São José, Tiradentes, MG, Brasil
}

\author{
Anne Priscila Dias Gonzaga ${ }^{1,4}$, Ary Teixeira de Oliveira Filho ${ }^{1}$,Evandro Luiz Mendonça Machado ${ }^{1}$, \\ Peter Hargreaves ${ }^{2}$ e José Nivaldo de Menezes Machado ${ }^{3}$
}

Recebido em 30/03/2007. Aceito em 11/07/2007

\begin{abstract}
RESUMO - (Diagnóstico florístico-estrutural do componente arbóreo da floresta da Serra de São José, Tiradentes, MG, Brasil). O presente estudo descreve a composição de espécies e estrutura fisionômica do componente arbóreo de uma área de Floresta Estacional Semidecídua Inferomontana/Altomontana situada na serra de São José, Tiradentes, Minas Gerais, Brasil. São feitas comparações florísticas e estruturais com outras 23 áreas de floresta da região do Alto Rio Grande, utilizando análise de correspondência canônica e discriminando as relações com variáveis ambientais e espaciais. As análises florísticas indicaram que, apesar de seu caráter de transição entre florestas inferomontanas e altomontanas, a flora arbórea da serra de São José tem laços mais fortes com as primeiras. As variações florísticas e estruturais entre as 24 florestas se relacionaram significativamente com a altitude, a duração da estação seca e a saturação por base dos solos. Apesar disso, também foi encontrada significativa correlação com a proximidade espacial entre as áreas.
\end{abstract}

Palavras-chave: altitude, análise multivariada, clima, Geoestatística, Floresta semidecídua, solos

ABSTRACT - (Floristic and structural diagnosis of the tree component of a forest at Serra de São José, Tiradentes, Minas Gerais State, Southeast Brazil). This work describes species composition and structure of the tree component of an area of lower to upper montane seasonal semideciduous forest located at Serra de São José, Tiradentes, SE Brazil. Floristic and structural comparisons are made with 23 other forest areas of the region using canonical correspondence analysis differentiating environmental and spatial variables. The floristic analyses indicated that, despite the transitional character between lower and upper montane forests, the tree flora of Serra de São José showed stronger link than the former. Floristic and structural variation among the 24 forests was significantly related to altitude, duration of the dry season and soil saturation of bases. Furthermore, a significant correlation was also found with spatial proximity of the areas.

Key words: altitude, multivariate analysis, climate, Geostatistics, Semideciduous forest, soils

\section{Introdução}

A região do Alto Rio Grande, sul de Minas Gerais, definida pelas coordenadas $21^{\circ} 00^{\prime}$ a $22^{\circ} 20^{\prime} \mathrm{S}$ e $43^{\circ} 40^{\prime}$ a $45^{\circ} 30^{\prime} \mathrm{W}$, compreende a bacia do Rio Grande a montante do reservatório hidroelétrico de Furnas, cujo curso encontra-se em boa parte represado pelos reservatórios de Itutinga, Camargos e Funil. A vegetação original da região abrangia um complexo mosaico formado por manchas de floresta, cerrado, campo de altitude e campo rupestre (Eiten 1982). Vários testemunhos datados do início da colonização desta região descrevem uma paisagem bastante diversa, incluindo extensas áreas de floresta intactas até a vinda do imigrante europeu (Pereira et al. 2006). Esta considerável variação deve-se principalmente ao fato de a região abrigar uma das áreas de transição entre os cerrados do Brasil Central e as florestas semidecíduas do Domínio Atlântico, transição esta que ocorre nas acidentadas vertentes continentais da serra da Mantiqueira, o que incrementa a heterogeneidade ambiental e, por conseguinte, também a biológica (Oliveira Filho et al. 1994b).

Variações altitudinais, como as observadas na serra da Mantiqueira, são comumente correspondidas por variações marcantes da composição de espécies e estrutura fisionômica das florestas tropicais (Proctor et al. 1988; Lieberman et al. 1995; 1996; Pendry \& Proctor 1996). Ao longo do gradiente altitudinal, muitos fatores do complexo ambiental, tais como temperatura, precipitação pluviométrica, umidade (do ar e do solo), velocidade dos ventos e outros, mudam simultanea-

\footnotetext{
Universidade Federal de Lavras, Departamento de Ciências Florestais, C. Postal 3037, 37200-000 Lavras, MG, Brasil

2 Universidade Federal de Lavras, Programa de Pós-Graduação em Engenharia Florestal, 37200-000 Lavras, MG, Brasil

Floresta Nacional (FLONA) de Ritápolis, Fazenda do Pombal - BR 294, Km 4, C. Postal 77, 36335-000 Ritápolis, MG, Brasil

4 Autor para correspondência: diaspri@gmail.com
} 
mente (Moreno et al. 2003). Estas mudanças é que propiciam heterogeneidade ambiental mais elevada que a de áreas menos acidentadas e, por conseguinte, maior diversidade florística. Oliveira Filho et al. (1994a), comparando 30 áreas da região sudeste, afirmaram que a altitude, ao determinar variações climáticas, provavelmente seria o fator mais intimamente relacionado com a diferenciação florística das florestas semidecíduas da região.

Semelhante ao ocorrido em vários outros estados do país, onde os processos de ocupação e exploração intensivos remontam ao período colonial, a cobertura florestal primitiva da região do Alto Rio Grande foi reduzida a remanescentes esparsos, a maioria deles bastante perturbada pelo fogo, pecuária extensiva e retirada seletiva de madeira (Oliveira Filho et al. 1994a). As florestas semidecíduas, em particular, foram criticamente reduzidas, visto que estas ocorrem em solos relativamente mais férteis e úmidos e, por conseguinte, mais visados pela agropecuária (van den Berg \& Oliveira Filho 2000). Como o processo de fragmentação florestal na região é muito antigo, este seguramente afetou as comunidades vegetais remanescentes, alterando sua composição, diversidade e estrutura fisionômica. Logo, é de grande importância que se realizem estudos que descrevam as comunidades vegetais e as variáveis ambientais a elas associadas, para que haja uma noção da diversidade restante e de sua distribuição na paisagem.

Nos últimos 20 anos, a região do Alto Rio Grande tem sido foco de muitas iniciativas de pesquisa, que foram iniciadas na década de 80 , quando pesquisadores da Universidade Federal de Lavras (UFLA) realizaram os primeiros levantamentos descritivos de fragmentos florestais da região, que já totalizam 24 fragmentos na atualidade (Pereira et al. 2006). Tais estudos têm buscado expandir o conhecimento sobre a flora e a estrutura dos remanescentes florestais da região e suas interações com variáveis do ambiente físico, tanto no espaço como no tempo, com o propósito de subsidiar programas e políticas para conservação e recuperação dos atuais fragmentos florestais. No mesmo contexto, o presente estudo teve como objetivo descrever a estrutura comunitária do componente arbóreo de um fragmento de floresta semidecídua montana, situado na Serra de São José, em Tiradentes, MG, e compará-lo, quanto aos aspectos estruturais e florísticos, com outros 23 remanescentes de floresta semidecídua montana e altomontana inventariados na região do Alto Rio Grande, relacionando os padrões diferenciais com variáveis ambientais. A hipótese de partida é que a altitude, como variável ambiental complexa, exerce papel preponderante nas variações florísticas e estruturais das florestas da região.

\section{Material e métodos}

Área de estudo - O presente estudo foi conduzido no remanescente florestal que reveste os sopés da vertente meridional da serra de São José, em Tiradentes, Minas Gerais, localizado entre as coordenadas $21^{\circ} 05^{\prime} 05^{\prime \prime}$ a $21^{\circ} 06^{\prime} 50^{\prime \prime} \mathrm{S}$ e $44^{\circ} 09^{\prime} 45^{\prime \prime}$ a $44^{\circ} 11^{\prime} 30^{\prime \prime W G W}$ (Fig. 1). A floresta cobre uma área de 1.013 ha, que se estende no sentido nordestesudoeste, em altitudes que variam entre 920 e $1.340 \mathrm{~m}$. De acordo com o sistema de Veloso et al. (1991), adotado pelo IBGE, a vegetação se classifica como Floresta Estacional Semidecidual Montana. O clima é do tipo Cwb de Köppen (mesotérmico com verões brandos e suaves e estiagens de inverno). A precipitação e a temperatura médias anuais são de $1.559 \mathrm{~mm}$ e $19,7{ }^{\circ} \mathrm{C}$, respectivamente, com $66 \%$ da precipitação ocorrendo de novembro a fevereiro (Vilela \& Ramalho 1979). Os solos foram classificados, segundo o Sistema Brasileiro de Classificação de Solo da Embrapa (2000) como Argissolos VermelhoAmarelos Distróficos típicos (PVAd) (Oliveira Filho \& Machado 1993).

Inventário do componente arbóreo - Foram alocadas 18 transeções amostrais de $10 \times 50 \mathrm{~m}$, as quais foram subdivididas em cinco parcelas adjacentes de $10 \times 10 \mathrm{~m}$, totalizando 90 parcelas e uma área amostral de 0,9 ha. As 18 transeções foram distribuídas sistematicamente em seis setores do remanescente florestal da serra de São José (A a F) e dispostas no sentido $40^{\circ} \mathrm{NW}$, que corresponde à maior declividade na maior parte da encosta (Fig. 1). Foram dispostas três transeções nos setores $\mathrm{B}, \mathrm{C}, \mathrm{E}$ e F, duas no A e quatro no D. As distâncias entre transeções foram de $100 \mathrm{~m}$ e, entre setores, de $1.000 \mathrm{~m}$, exceto entre $\mathrm{C}$ e $\mathrm{D}$, onde foi de $700 \mathrm{~m}$, para se evitar a inclusão em área desmatada. Todos os indivíduos arbóreos vivos, presentes nas parcelas, com diâmetro à altura do peito $(\mathrm{DAP}) \geq 5 \mathrm{~cm}$ foram identificados, sua circunferência à altura do peito (CAP) foi medida com fita métrica e sua altura total foi estimada com auxílio de uma vara graduada. As espécies foram classificadas em famílias de acordo com o sistema do Angiosperm Phylogeny Group II (APG II 2003). O material botânico coletado foi herborizado e depositado no Herbário do Departamento de Biologia da Universidade Federal de Lavras 


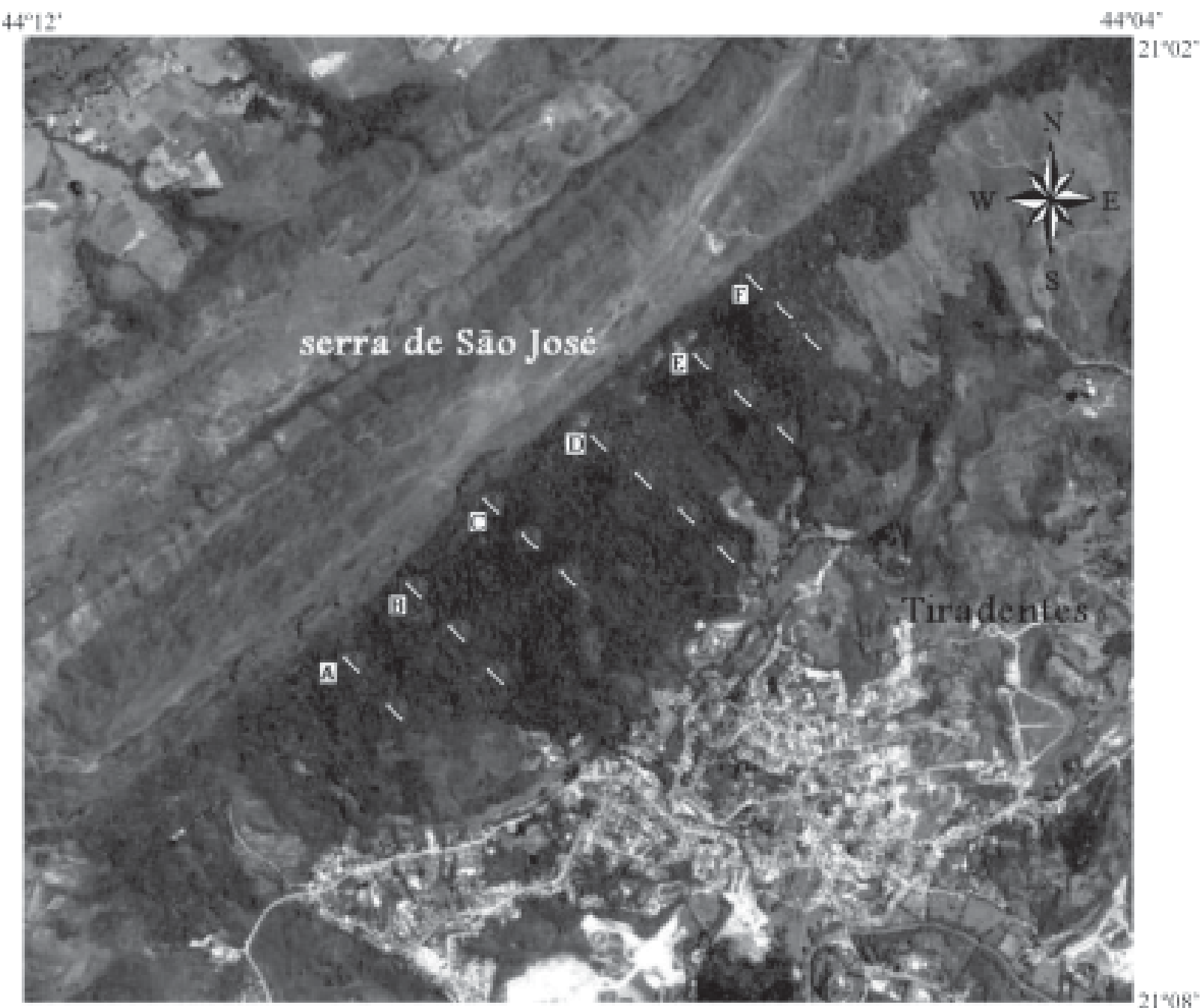

Figura 1. Distribuição das 18 transeções amostrais de 10×50 m na floresta da serra de São José, Tiradentes, MG, Brasil.

(Herbário ESAL). Para descrição da estrutura da comunidade arbórea, foram calculados os seguintes parâmetros estruturais, segundo Mueller-Dombois \& Ellenberg (1974): densidade absoluta (DA), dominância absoluta (DoA) derivada da área basal à altura do peito, freqüência absoluta (FA), densidade relativa (DR), dominância relativa (DoR), freqüência relativa (FR) e valor de importância (VI). A diversidade de espécies arbóreas da amostra foi avaliada pela riqueza (número de espécies) e índices de diversidade de Shannon (H') e de equabilidade de Pielou (J') (Brower \& Zar 1984).

Análises florísticas e estruturais - Para realizar o diagnóstico florístico e estrutural da floresta da serra de São José em um contexto comparativo, foram extraídas da literatura informações ambientais e sobre o componente arbóreo de outros 23 remanescentes florestais inventariados na região do Alto Rio Grande.
A situação geográfica das 24 áreas é indicada na Fig. 2, ao passo que informações geográficas, climáticas e vegetacionais são fornecidas na Tab. 1. Para o componente arbóreo de cada área, foram extraídas as listagens completas de espécies e a relação de parâmetros quantitativos daquelas amostradas nos inventários, todos eles realizados com o mesmo critério de inclusão de árvores descrito no presente estudo. A densidade relativa foi escolhida como parâmetro quantitativo para as análises, por não apresentar discrepâncias tão fortes entre as espécies mais abundantes, como é tipicamente registrado para a dominância extraída da área basal (Scudeller et al. 2001).

Para subsidiar as análises, foram obtidas variáveis ambientais de natureza climática, topográfica e edáfica para as 24 áreas. As variáveis climáticas foram extraídas das médias anuais e mensais de temperatura 
e precipitação fornecidas pelo DNMET (1992) ou pela Rede Nacional de Agrometeorologia (2004). Para algumas áreas, no entanto, as médias foram geradas a partir de interpolação entre registros de áreas vizinhas e/ou aplicação de correção para altitude, seguindo procedimentos descritos por Thornthwaite (1948). As variáveis climáticas foram: temperatura média anual, mensal mais fria e mensal mais quente; precipitação média anual, mensal do trimestre mais chuvoso e mensal do trimestre mais seco; e duração média da estação seca derivada de diagramas de Walter (1985).
As variáveis topográficas foram extraídas de levantamentos planialtimétricos conduzidos nas áreas amostrais dos 24 áreas de floresta, com auxílio de um hipsômetro de Suunto para medir a inclinação do terreno. Como meio de avaliação indireta do regime de água dos solos e seguindo procedimento descrito por Oliveira Filho et al. (1990; 1994b), foram produzidas, para cada parcela amostral das 24 áreas de floresta, quatro variáveis topográficas obtidas a partir da cota altitudinal dos vértices das parcelas: a) 'altitude média', obtida a partir da média das quatro

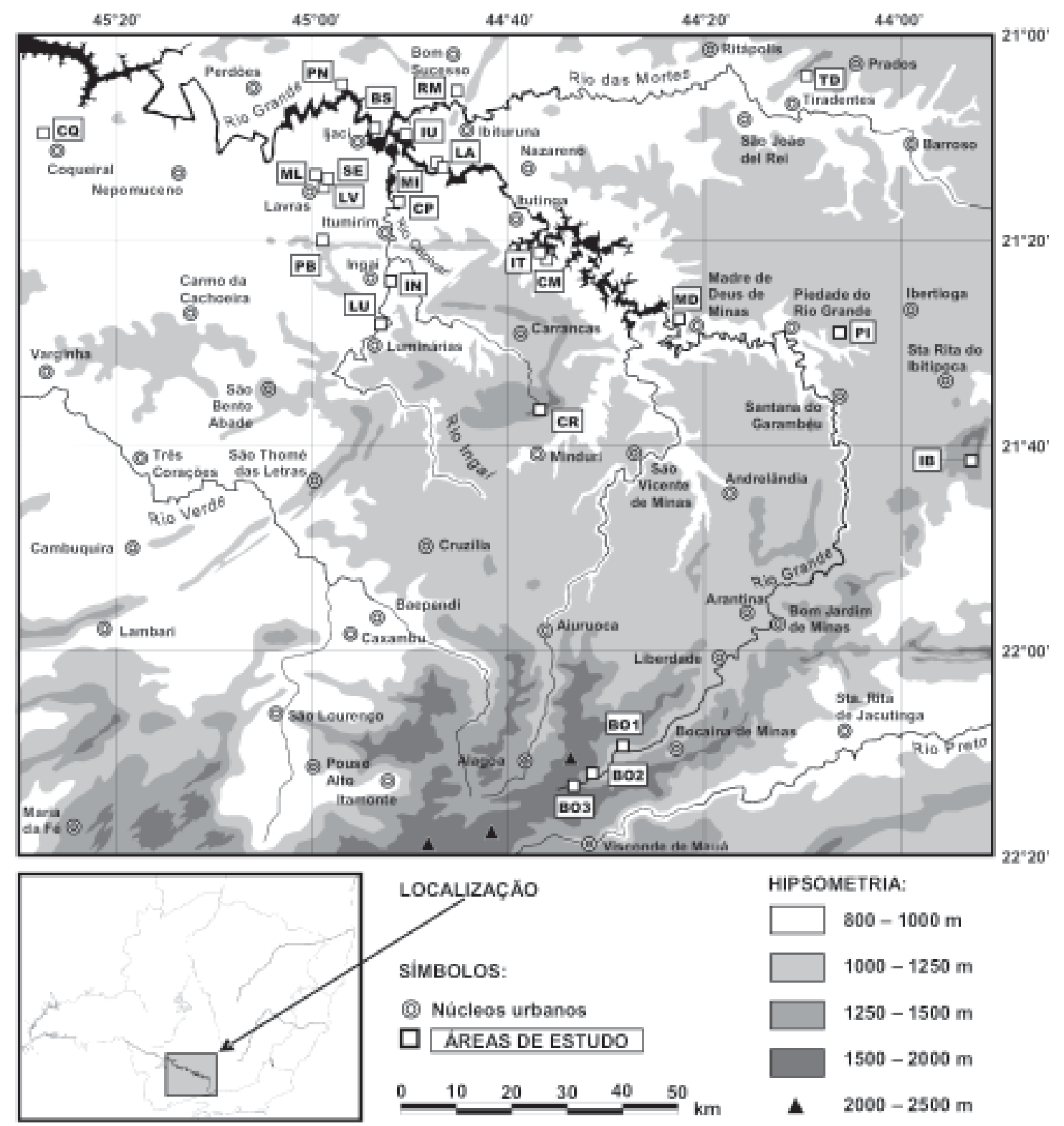

Figura 2. Mapa altimétrico da região do Alto Rio Grande, MG, Brasil mostrando a localização das 24 áreas de floresta utilizadas nas análises florística e estrutural do componente arbóreo da floresta da serra de São José, Tiradentes, Minas Gerais, indicada como TD. Vide identificação das áreas na Tab. 1 . 


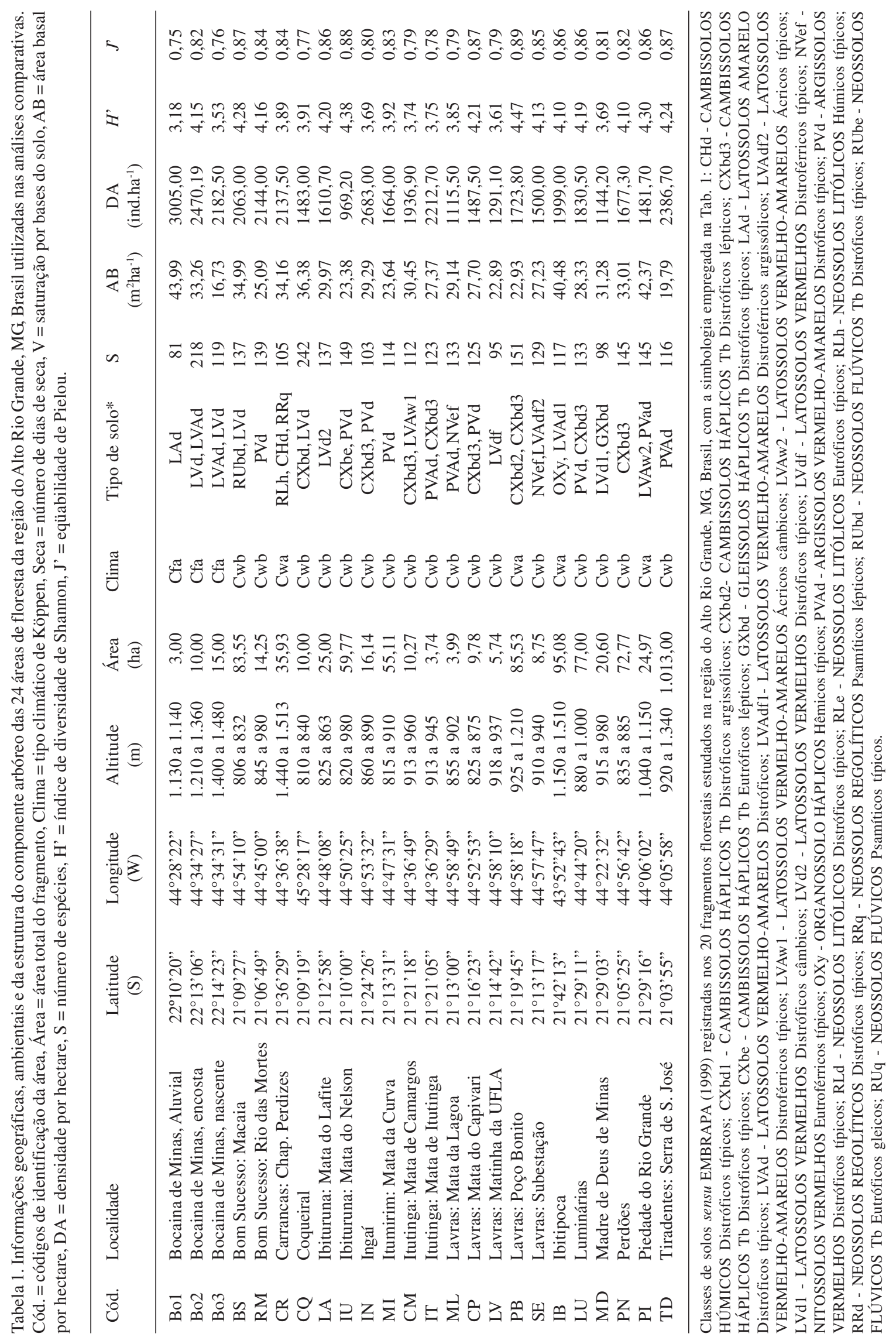


cotas dos vértices; b) 'desnível', obtido pela diferença entre as cotas máxima e mínima; c) 'distância vertical' até o curso d'água, obtida da diferença entre a cota média dos vértices e a cota do curso d'água, e d) 'distância horizontal' até o curso d'água, obtida pela mensuração da distância do centro da parcela até a margem. Foram obtidas médias das quatro variáveis topográficas para cada uma das 24 áreas.

As variáveis edáficas foram obtidas a partir de análises laboratoriais de amostras do solo superficial $(0-20 \mathrm{~cm})$ coletadas amostras compostas em todas as parcelas amostrais de cada área de floresta. As análises químicas e texturais foram realizadas no Laboratório de Análise de Solos da Universidade Federal de Lavras, segundo o protocolo da Embrapa (1997), obtendo-se as seguintes variáveis: $\mathrm{pH}$; teores de $\mathrm{P}, \mathrm{K}^{+}, \mathrm{Ca}^{++}, \mathrm{Mg}^{++}$ e $\mathrm{Al}^{+++}$; soma de bases (S); saturação por bases (V) e por alumínio (m); e proporções de matéria orgânica, areia, silte e argila. Foram obtidas médias das 13 variáveis edáficas para cada uma das 24 áreas de floresta.

Para analisar as variações em composição florística (qualitativa) e abundância das espécies (quantitativa) do componente arbóreo das 24 áreas de floresta e suas correlações com variáveis ambientais, foi adotada a análise de correspondência canônica (CCA, ter Braak 1987), executada com uso do programa CANOCO 4.5 (ter Braak \& Smilauer 1998) e seguindo o procedimento proposto por Borcard et al. (1992) para discriminar os componentes ambientais e espaciais na explicação dos padrões emergentes da distribuição de espécies. Este procedimento exige a preparação de três matrizes com informações multivariadas sobre as unidades amostrais, no caso, as 24 áreas de floresta. São elas a matriz das espécies, a matriz ambiental e a matriz espacial.

Duas matrizes de espécies foram preparadas para o presente estudo, uma qualitativa e outra quantitativa, para realização de duas análises independentes para estes dois aspectos do componente arbóreo das áreas de floresta. A matriz qualitativa de espécies, ou matriz florística, consistiu dos dados binários de presença (1) ou ausência (0) de espécies nas 24 áreas, ao passo que a matriz quantitativa ou estrutural consistiu da densidade relativa (DR) das espécies nas áreas. Como recomendado por ter Braak (1995), os valores de abundância na matriz quantitativa foram transformados pela expressão $\ln (\mathrm{DR}+1)$ antes de se processar a análise, porque suas distribuições eram tipicamente distorcidas no sentido de poucos valores muito elevados. A matriz ambiental consistiu das sete variáveis climáticas, quatro variáveis topográficas e 13 variáveis edáficas de cada área de floresta. A matriz espacial consistiu das coordenadas geográficas, latitude (lat) e longitude (lon), das 24 áreas mais as nove variáveis derivadas por meio do modelo polinomial proposto por Borcard et al. (1992): lat ${ }^{2}$, lon $^{2}$, lat $^{3}$, lon $^{3}$, lat*lon, lat ${ }^{2 *}$ lon e lat*lon ${ }^{2}$.

Seguindo a rotina de Borcard et al. (1992), foram realizadas quatro CCAs relacionando a matriz de espécies com variáveis ambientais (CCA1), variáveis espaciais (CCA2), variáveis ambientais e co-variáveis espaciais (CCA3) e variáveis espaciais e co-variáveis ambientais (CCA4). Nas CCAs 1 e 2, foi utilizada a rotina de seleção progressiva de variáveis ambientais, associada a testes de Monte Carlo, para verificação de significância, sendo as variáveis selecionadas utilizadas nas CCAs 3 e 4 . Nas CCAs realizadas com a matriz qualitativa de espécies, o processo preservou somente três variáveis ambientais: altitude média, duração da estação seca e saturação por base dos solos (V), e duas variáveis espaciais: lat e $\operatorname{lon}^{3}$. Nas CCAs realizadas com a matriz quantitativa de espécies, as variáveis ambientais foram coincidentemente as mesmas, mas as espaciais foram outras: lat ${ }^{2}$ e $\operatorname{lon}^{3}$. Testes de Monte Carlo (ter Braak 1988) foram aplicados às oito CCAs das análises florística e estrutural e seus resultados foram empregados para estimar a proporção da variação dos dados das espécies que é explicada distintamente pelas variáveis ambientais e espaciais, bem como a proporção explicada indistintamente pelos dois conjuntos de variáveis e a variação remanescente que não pôde ser explicada por nenhuma das variáveis em questão.

Para analisar diretamente a similaridade e/ou dissimilaridade florística entre a floresta da serra de São José e os conjuntos de florestas Inferomontanas e Altomontanas foi confeccionado um diagrama de Venn, com base na presença e ausência das espécies, e calculados índices de similaridade de Sørensen (Brower \& Zar 1984). Ao se aglutinarem as áreas de florestas nas duas categorias, duas delas: MD (Madre de Deus) e BO1 (Bocaina de Minas - Fragmento 1) foram excluídas por apresentarem flora muito distinta, provavelmente devido à presença de aluviões inundáveis.

\section{Resultados e discussão}

Composição florística e estrutura - A amostra do componente arbóreo da floresta da serra de São José (TD) apresentou 2.148 indivíduos, que se distribuíram 
em 130 espécies, 92 gêneros e 48 famílias (Tab. 2). As cinco famílias de maior riqueza florística foram Fabaceae com 18 espécies (11 Faboideae, quatro Mimosoideae, três Caesalpinioideae), Myrtaceae com 12, Melastomataceae com nove, Rubiaceae com sete, Lauraceae com seis e Sapindaceae com cinco, representando $51,3 \%$ da flora total. Os dez gêneros que apresentaram maior riqueza florística e o respectivo número de espécies foram: Miconia com seis, Machaerium e Protium com quatro, Casearia, Cupania, Eremanthus, Myrcia, Myrsine, Ocotea e Tibouchina com três. Já os gêneros que contribuíram com os maiores números de indivíduos foram: Tapirira (185 indivíduos), Myrcia (170), Machaerium (131), Copaifera (78), Myrsine (77), Vismia (75), Protium (73), Piptadenia (55) e Vochysia (50).

Quando se comparam os perfis florísticos da Serra de São José com o de florestas de altitude estudadas por Oliveira Filho \& Fontes (2000), observa-se que as famílias mais representativas nesse estudo também ocuparam as primeiras posições nesse rank, com exceção de Sapindaceae. Contudo é importante ressaltar que, embora as famílias ocorram com elevada importância em ambos os estudos, a ordem de ocupação destas no rank é bastante divergente, por exemplo, para a Serra de José a família com maior representatividade foi Fabaceae, contudo na listagem obtida por Oliveira Filho \& Fontes (2000), esta família ocupa a quinta colocação. O oposto pode ser observado para Myrtaceae, que ocupa a primeira posição em florestas com elevado grau altitudinal e ocupa a segunda posição na serra de São José, assim como para Lauraceae que ocupava a terceiro lugar no rank das mais importantes nas primeiras e a quinta colocação em Tiradentes. Já na comparação para os gêneros entre os estudos mencionados, apenas Miconia, Machaerium, Casearia, Myrcia, Myrsine, Ocotea e Tibouchina são compartilhados entre os mais importantes, sendo conveniente ressaltar que em ambos Miconia se apresentou com valores bastante expressivos.

Este padrão de distribuição, tanto das famílias como dos gêneros, é freqüente na literatura, onde se observa diminuição da contribuição de Fabaceae à medida que o gradiente altitudinal aumenta. Contudo, padrão inverso é observado para Lauraceae e Myrtaceae, cuja contribuição aumenta ao passo que a altitude se torna mais elevada (Gentry 1995). Desta forma, quando se analisa em nível de gênero, Eremanthus, Myrsine e Ocotea são gêneros que tendem a aumentar sua abundância à medida que o grau de altitude se torna mais elevado.
Desta forma, com os padrões encontrados, pode-se sugerir que a Serra de São José, provavelmente, encontra-se em grau altitudinal intermediário, já que agrupa em sua flora algumas peculiaridades das Florestas Ínferomontanhas, como o elevado número de espécies de Fabaceae, porém apresenta também características de áreas com gradiente de altitude mais elevado, como por exemplo, o aumento da contribuição de Lauraceae e Myrtaceae, dentre outras, em sua flora.

As dez espécies com maior densidade, totalizando $36,40 \%$ do número total de indivíduos, foram Tapirira guianensis (8,51\%), Myrcia splendens (5,58\%), Copaifera langsdorffii (3,63\%), Vismia brasiliensis $(3,49 \%)$, Myrsine umbellata (3,16\%), Machaerium scleroxylon (2,74\%), Piptadenia gonoacantha $(2,56 \%)$, Vochysia magnifica $(2,28 \%)$, Protium widgrenii $(2,23)$ Clethra scabra $(2,18 \%)$. Os dez maiores valores de área basal foram registrados para as espécies: T. guianensis $(7,44 \%), P$. gonoacantha $(4,27 \%)$, V. magnifica $(4,00 \%)$, Lafoensia pacari $(3,89 \%)$, C. langsdorffii $(3,72 \%)$, M. splendens $(3,45 \%)$, V. brasiliensis (3,26\%), Machaerium villosum (3,22\%), C. scabra $(2,88 \%)$ e Eremanthus erythropappus (2,36\%), compreendendo 38,54\% da área basal total. Dentre estas, apenas duas, Clethra scabra e Vismia brasiliensis, são espécies que podem ocorrer com grande freqüência em áreas com altitude mais elevada (Oliveira Filho et al. 2004). Dentre as espécies amostradas neste estudo, apenas Hedyosmum brasiliense foi citado por Oliveira Filho \& Fontes (2000) como típica de florestas de maior altitude. No entanto, $V$. brasiliensis, $C$. scabra e $H$. brasiliensis podem ocorrer em florestas de restinga e, portanto, não são exclusivas de florestas montanas. Provavelmente fazem parte de um conhecido grupo de espécies adaptadas ao stress dos ambientes marginais e da Mata Atlântica seja em seus limites oceânicos, altitudinais, paludosos ou rupícolas (Scarano 2002; Scarano et al. 2005). A única exceção é E. erythropappus, uma espécie típica apenas das fronteiras altitudinais e rupícolas da Mata Atlântica (Oliveira Filho \& Fluminhan Filho 1999). Tais fatos sugerem a hipótese de que a Serra de São José se encontra em zona de transição florística entre as formações Inferomontanas e Altomontanas, porém tendendo a maior aproximação florística com as primeiras, visto que compartilham número maior de espécies com estas formações.

Os índices de diversidade de Shannon e equabilidade de Pielou foram, respectivamente, $H^{\prime}=4,23$ e $J^{\prime}=0,87$. Se comparados com as outras 
Tabela 2. Famílias e espécies amostradas, com seus respectivos parâmetros estruturais, na Serra de São José, Tiradentes, MG, Brasil. $\mathrm{Ni}=$ Número de indivíduos amostrados; $\mathrm{AB}=$ área basal da espécie; $\mathrm{Np}=$ número de parcelas; $\mathrm{DA}=$ Densidade absoluta (ind.ha ${ }^{-1}$ ); DR = Densidade Relativa (\%); DoA = Dominância Absoluta $\left(\mathrm{m}^{2} \cdot \mathrm{ha}^{-1}\right) ; \mathrm{DoR}=$ Dominância Relativa (\%); FA = Frequiência Absoluta $(\%)$; $\mathrm{FR}=$ Frequiência Relativa (\%); VI= Valor de Importância (\%).

\begin{tabular}{|c|c|c|c|c|c|c|c|c|c|c|}
\hline Família/Espécie & $\mathrm{Ni}$ & $\begin{array}{l}\mathrm{AB} \\
\left(\mathrm{m}^{2}\right)\end{array}$ & $\mathrm{Np}$ & $\begin{array}{c}\text { DA } \\
\left.\text { (ind.ha }{ }^{-1}\right)\end{array}$ & $\begin{array}{l}\mathrm{DR} \\
(\%)\end{array}$ & $\begin{array}{c}\text { DoA } \\
\left(\mathrm{m}^{2} \cdot h \mathrm{~h}^{-1}\right)\end{array}$ & $\begin{array}{l}\text { DoR } \\
(\%)\end{array}$ & $\begin{array}{l}\text { FA } \\
(\%)\end{array}$ & $\begin{array}{l}\text { FR } \\
(\%)\end{array}$ & $\begin{array}{l}\mathrm{VI} \\
(\%)\end{array}$ \\
\hline \multicolumn{11}{|l|}{ ANACARDIACEAE } \\
\hline Lithraea molleoides (Vell.) Engl. & 36 & 0,241 & 5 & 40,00 & 1,68 & 0,27 & 1,35 & 27,78 & 0,86 & 3,89 \\
\hline Schinus terebinthifolius Raddi & 9 & 0,038 & 4 & 10,00 & 0,42 & 0,04 & 0,22 & 22,22 & 0,69 & 1,32 \\
\hline Tapirira guianensis Aubl. & 183 & 1,326 & 16 & 203,33 & 8,52 & 1,47 & 7,44 & 88,89 & 2,75 & 18,72 \\
\hline T. obtusa (Benth.) J.D. Mitch. & 2 & 0,011 & 2 & 2,22 & 0,09 & 0,01 & 0,06 & 11,11 & 0,34 & 0,50 \\
\hline \multicolumn{11}{|l|}{ ANNONACEAE } \\
\hline Annona cacans Warm. & 20 & 0,249 & 7 & 22,22 & 0,93 & 0,28 & 1,40 & 38,89 & 1,20 & 3,53 \\
\hline Guatteria australis A.St.-Hil. & 7 & 0,031 & 3 & 7,78 & 0,33 & 0,03 & 0,17 & 16,67 & 0,52 & 1,02 \\
\hline Rollinia sylvatica (A.St.-Hil.) Mart. & 1 & 0,017 & 1 & 1,11 & 0,05 & 0,02 & 0,09 & 5,56 & 0,17 & 0,31 \\
\hline \multicolumn{11}{|l|}{ APOCYNACEAE } \\
\hline Aspidosperma australe Müll. Arg. & 35 & 0,420 & 8 & 38,89 & 1,63 & 0,47 & 2,36 & 44,44 & 1,38 & 5,36 \\
\hline \multicolumn{11}{|l|}{ AQUIFOLIACEAE } \\
\hline $\begin{array}{l}\text { Dendropanax cuneatus (DC.) Decne. } \\
\text { \& Planch. }\end{array}$ & 12 & 0,076 & 3 & 13,33 & 0,56 & 0,08 & 0,43 & 16,67 & 0,52 & 1,50 \\
\hline Ilex cerasifolia Reissek & 3 & 0,024 & 2 & 3,33 & 0,14 & 0,03 & 0,13 & 11,11 & 0,34 & 0,62 \\
\hline I. conocarpa Reissek & 3 & 0,021 & 2 & 3,33 & 0,14 & 0,02 & 0,12 & 11,11 & 0,34 & 0,60 \\
\hline \multicolumn{11}{|l|}{ ASTERACEAE } \\
\hline $\begin{array}{l}\text { Eremanthus erythropappus (DC.) } \\
\text { MacLeish }\end{array}$ & 43 & 0,422 & 7 & 47,78 & 2,00 & 0,47 & 2,37 & 38,89 & 1,20 & 5,57 \\
\hline E. glomerulatus Less. & 1 & 0,004 & 1 & 1,11 & 0,05 & 0,00 & 0,02 & 5,56 & 0,17 & 0,24 \\
\hline E. incanus (Less.) Less. & 1 & 0,002 & 1 & 1,11 & 0,05 & 0,00 & 0,01 & 5,56 & 0,17 & 0,23 \\
\hline Gochnatia polymorpha (Less.) Cabrera & 6 & 0,066 & 3 & 6,67 & 0,28 & 0,07 & 0,37 & 16,67 & 0,52 & 1,17 \\
\hline \multicolumn{11}{|l|}{ BORAGINACEAE } \\
\hline Cordia sellowiana Cham. & 13 & 0,128 & 5 & 14,44 & 0,61 & 0,14 & 0,72 & 27,78 & 0,86 & 2,18 \\
\hline \multicolumn{11}{|l|}{ BURSERACEAE } \\
\hline Protium brasiliense (Spreng.) Engl. & 4 & 0,022 & 2 & 4,44 & 0,19 & 0,02 & 0,12 & 11,11 & 0,34 & 0,66 \\
\hline P. heptaphyllum (Aubl.) Marchand & 12 & 0,070 & 3 & 13,33 & 0,56 & 0,08 & 0,39 & 16,67 & 0,52 & 1,47 \\
\hline P. spruceanum (Benth.) Engl. & 9 & 0,069 & 3 & 10,00 & 0,42 & 0,08 & 0,39 & 16,67 & 0,52 & 1,32 \\
\hline P. widgrenii Engl. & 48 & 0,363 & 6 & 53,33 & 2,23 & 0,40 & 2,04 & 33,33 & 1,03 & 5,31 \\
\hline \multicolumn{11}{|l|}{ CELASTRACEAE } \\
\hline Maytenus gonoclada Mart. & 8 & 0,128 & 2 & 8,89 & 0,37 & 0,14 & 0,72 & 11,11 & 0,34 & 1,44 \\
\hline \multicolumn{11}{|l|}{ CHLORANTHACEAE } \\
\hline Hedyosmum brasiliense Mart. & 17 & 0,060 & 1 & 18,89 & 0,79 & 0,07 & 0,34 & 5,56 & 0,17 & 1,30 \\
\hline \multicolumn{11}{|l|}{ CLETHRACEAE } \\
\hline Clethra scabra Pers. & 47 & 0,513 & 8 & 52,22 & 2,19 & 0,57 & 2,88 & 44,44 & 1,38 & 6,45 \\
\hline \multicolumn{11}{|l|}{ CLUSIACEAE } \\
\hline Calophyllum brasiliense Cambess. & 1 & 0,016 & 1 & 1,11 & 0,05 & 0,02 & 0,09 & 5,56 & 0,17 & 0,31 \\
\hline Clusia criuva Cambess. & 18 & 0,169 & 3 & 20,00 & 0,84 & 0,19 & 0,95 & 16,67 & 0,52 & 2,30 \\
\hline Garcinia brasiliensis Mart. & 9 & 0,024 & 1 & 10,00 & 0,42 & 0,03 & 0,14 & 5,56 & 0,17 & 0,73 \\
\hline $\begin{array}{l}\text { Chrysochlamys saldanhae (Engl.) } \\
\text { Oliveira Filho }\end{array}$ & 15 & 0,102 & 5 & 16,67 & 0,70 & 0,11 & 0,57 & 27,78 & 0,86 & 2,13 \\
\hline \multicolumn{11}{|l|}{ CUNONIACEAE } \\
\hline Lamanonia ternata Vell. & 28 & 0,196 & 8 & 31,11 & 1,30 & 0,22 & 1,10 & 44,44 & 1,38 & 3,78 \\
\hline \multicolumn{11}{|l|}{ ERYTHROXYLACEAE } \\
\hline Erythroxylum citrifolium A. St.-Hil. & 1 & 0,005 & 1 & 1,11 & 0,05 & 0,01 & 0,03 & 5,56 & 0,17 & 0,25 \\
\hline \multicolumn{11}{|l|}{ EUPHORBIACEAE } \\
\hline Alchornea triplinervia (Spreng.) Müll. Arg. & 13 & 0,157 & 6 & 14,44 & 0,61 & 0,17 & 0,88 & 33,33 & 1,03 & 2,52 \\
\hline Croton floribundus Spreng. & 18 & 0,077 & 5 & 20,00 & 0,84 & 0,09 & 0,44 & 27,78 & 0,86 & 2,13 \\
\hline Mabea fistulifera Mart. & 2 & 0,008 & 1 & 2,22 & 0,09 & 0,01 & 0,05 & 5,56 & 0,17 & 0,31 \\
\hline Pera glabrata (Schott) Poepp. ex Baill. & 29 & 0,274 & 7 & 32,22 & 1,35 & 0,30 & 1,54 & 38,89 & 1,20 & 4,09 \\
\hline \multicolumn{11}{|l|}{ FABACEAE } \\
\hline Andira fraxinifolia Benth. & 21 & 0,094 & 9 & 23,33 & 0,98 & 0,10 & 0,53 & 50,00 & 1,55 & 3,05 \\
\hline Bowdichia virgilioides Kunth & 1 & 0,014 & 1 & 1,11 & 0,05 & 0,02 & 0,08 & 5,56 & 0,17 & 0,30 \\
\hline
\end{tabular}


Tabela 2 (continuação)

\begin{tabular}{|c|c|c|c|c|c|c|c|c|c|c|}
\hline Família/Espécie & $\mathrm{Ni}$ & $\begin{array}{l}\mathrm{AB} \\
\left(\mathrm{m}^{2}\right)\end{array}$ & $\mathrm{Np}$ & $\begin{array}{c}\text { DA } \\
\text { (ind.ha }{ }^{-1} \text { ) }\end{array}$ & $\begin{array}{l}\mathrm{DR} \\
(\%)\end{array}$ & $\begin{array}{c}\text { DoA } \\
\left(\mathrm{m}^{2} \cdot \mathrm{ha}^{-1}\right)\end{array}$ & $\begin{array}{l}\text { DoR } \\
(\%)\end{array}$ & $\begin{array}{l}\text { FA } \\
(\%)\end{array}$ & $\begin{array}{l}\text { FR } \\
(\%)\end{array}$ & $\begin{array}{l}\mathrm{VI} \\
(\%)\end{array}$ \\
\hline Cassia ferruginea (Schrad.) Schrad. ex DC. & 1 & 0,044 & 1 & 1,11 & 0,05 & 0,05 & 0,25 & 5,56 & 0,17 & 0,47 \\
\hline Copaifera langsdorffii Desf. & 78 & 0,664 & 12 & 86,67 & 3,63 & 0,74 & 3,73 & 66,67 & 2,07 & 9,42 \\
\hline Dalbergia brasiliensis Vogel & 2 & 0,005 & 2 & 2,22 & 0,09 & 0,01 & 0,03 & 11,11 & 0,34 & 0,47 \\
\hline D. villosa (Benth.) Benth. & 20 & 0,085 & 7 & 22,22 & 0,93 & 0,09 & 0,48 & 38,89 & 1,20 & 2,61 \\
\hline Inga ingoides (Rich.) Willd. & 8 & 0,045 & 2 & 8,89 & 0,37 & 0,05 & 0,25 & 11,11 & 0,34 & 0,97 \\
\hline I. striata Benth. & 14 & 0,321 & 3 & 15,56 & 0,65 & 0,36 & 1,80 & 16,67 & 0,52 & 2,97 \\
\hline $\begin{array}{l}\text { Leucochloron incuriale (Vell.) Barneby \& } \\
\text { J.W. Grimes }\end{array}$ & 10 & 0,052 & 5 & 11,11 & 0,47 & 0,06 & 0,29 & 27,78 & 0,86 & 1,62 \\
\hline Machaerium hirtum (Vell.) Stellfeld & 5 & 0,080 & 3 & 5,56 & 0,23 & 0,09 & 0,45 & 16,67 & 0,52 & 1,20 \\
\hline M. nictitans (Vell.) Benth. & 22 & 0,340 & 8 & 24,44 & 1,02 & 0,38 & 1,91 & 44,44 & 1,38 & 4,31 \\
\hline M. scleroxylon Tul. & 59 & 0,403 & 7 & 65,56 & 2,75 & 0,45 & 2,26 & 38,89 & 1,20 & 6,21 \\
\hline M. villosum Vogel & 45 & 0,574 & 14 & 50,00 & 2,09 & 0,64 & 3,22 & 77,78 & 2,41 & 7,73 \\
\hline Ormosia fastigiata Tul. & 2 & 0,025 & 2 & 2,22 & 0,09 & 0,03 & 0,14 & 11,11 & 0,34 & 0,58 \\
\hline Piptadenia gonoacantha (Mart.) J.F. Macbr. & 55 & 0,761 & 5 & 61,11 & 2,56 & 0,85 & 4,27 & 27,78 & 0,86 & 7,69 \\
\hline Platycyamus regnellii Benth. & 1 & 0,006 & 1 & 1,11 & 0,05 & 0,01 & 0,03 & 5,56 & 0,17 & 0,25 \\
\hline Platypodium elegans Vogel & 6 & 0,069 & 2 & 6,67 & 0,28 & 0,08 & 0,39 & 11,11 & 0,34 & 1,01 \\
\hline $\begin{array}{l}\text { Senna macranthera (Collad.) H.S.Irwin \& } \\
\text { Barneby }\end{array}$ & 9 & 0,066 & 7 & 10,00 & 0,42 & 0,07 & 0,37 & 38,89 & 1,20 & 2,00 \\
\hline \multicolumn{11}{|l|}{ HYPERICACEAE } \\
\hline Vismia brasiliensis Choisy & 75 & 0,581 & 12 & 83,33 & 3,49 & 0,65 & 3,26 & 66,67 & 2,07 & 8,82 \\
\hline \multicolumn{11}{|l|}{ LACISTEMATACEAE } \\
\hline Lacistema hasslerianum Chodat & 2 & 0,006 & 2 & 2,22 & 0,09 & 0,01 & 0,03 & 11,11 & 0,34 & 0,47 \\
\hline \multicolumn{11}{|l|}{ LAMIACEAE } \\
\hline Aegiphila sellowiana Cham. & 2 & 0,010 & 2 & 2,22 & 0,09 & 0,01 & 0,06 & 11,11 & 0,34 & 0,49 \\
\hline Hyptidendron asperrimum (Epling) Harley & 5 & 0,013 & 2 & 5,56 & 0,23 & 0,01 & 0,07 & 11,11 & 0,34 & 0,65 \\
\hline Vitex polygama Cham. & 18 & 0,089 & 7 & 20,00 & 0,84 & 0,10 & 0,50 & 38,89 & 1,20 & 2,54 \\
\hline \multicolumn{11}{|l|}{ LAURACEAE } \\
\hline Cryptocarya aschersoniana $\mathrm{Mez}$ & 15 & 0,363 & 9 & 16,67 & 0,70 & 0,40 & 2,04 & 50,00 & 1,55 & 4,29 \\
\hline Nectandra oppositifolia Nees & 30 & 0,300 & 11 & 33,33 & 1,40 & 3 & 1,68 & 61,11 & 1,89 & 4,97 \\
\hline Ocotea corymbosa (Meisn.) Mez & 34 & 0,371 & 14 & 37,78 & 1,58 & 0,41 & 2,08 & 77,78 & 2,41 & 6,08 \\
\hline O. glaziovii $\mathrm{Mez}$ & 5 & 0,025 & 1 & 5,56 & 0,23 & 0,03 & 0,14 & 5,56 & 0,17 & 0,55 \\
\hline O. pulchella Mart. & 9 & 0,058 & 7 & 10,00 & 0,42 & 0,06 & 0,33 & 38,89 & 1,20 & 1,95 \\
\hline Persea major L.E.Kopp & 17 & 0,251 & 5 & 18,89 & 0,79 & 0,28 & 1,41 & 27,78 & 0,86 & 3,06 \\
\hline \multicolumn{11}{|l|}{ LYTHRACEAE } \\
\hline Lafoensia vandelliana Cham. \& Schltdl. & 33 & 0,694 & 7 & 36,67 & 1,54 & 0,77 & 3,90 & 38,89 & 1,20 & 6,64 \\
\hline \multicolumn{11}{|l|}{ MAGNOLIACEAE } \\
\hline Magnolia ovata (A. St.-Hil.) Spreng. & 3 & 0,009 & 1 & 3,33 & 0,14 & 0,01 & 0,05 & 5,56 & 0,17 & 0,36 \\
\hline \multicolumn{11}{|l|}{ MALVACEAE } \\
\hline Ceiba speciosa (A. St.-Hil.) Ravenna & 1 & 0,007 & 1 & 1,11 & 0,05 & 0,01 & 0,04 & 5,56 & 0,17 & 0,26 \\
\hline Guazuma ulmifolia Lam. & 9 & 0,052 & 7 & 10,00 & 0,42 & 0,06 & 0,29 & 38,89 & 1,20 & 1,92 \\
\hline Luehea divaricata Mart. & 11 & 0,047 & 7 & 12,22 & 0,51 & 0,05 & 0,27 & 38,89 & 1,20 & 1,98 \\
\hline L. grandiflora Mart. \& Zucc. & 9 & 0,111 & 6 & 10,00 & 0,42 & 0,12 & 0,62 & 33,33 & 1,03 & 2,08 \\
\hline \multicolumn{11}{|l|}{ MELASTOMATACEAE } \\
\hline Miconia argyrophylla DC. & 3 & 0,058 & 2 & 3,33 & 0,14 & 0,06 & 0,32 & 11,11 & 0,34 & 0,81 \\
\hline M. chartacea Triana & 4 & 0,018 & 3 & 4,44 & 0,19 & 0,02 & 0,10 & 16,67 & 0,52 & 0,80 \\
\hline M. cinnamomifolia (DC.) Naudin & 8 & 0,152 & 3 & 8,89 & 0,37 & 0,17 & 0,86 & 16,67 & 0,52 & 1,74 \\
\hline M. latecrenata (DC.) Naudin & 1 & 0,004 & 1 & 1,11 & 0,05 & 0,00 & 0,02 & 5,56 & 0,17 & 0,24 \\
\hline M. minutiflora (Bonpl.) DC. & 1 & 0,002 & 1 & 1,11 & 0,05 & 0,00 & 0,01 & 5,56 & 0,17 & 0,23 \\
\hline M. trianaei Cogn. & 14 & 0,115 & 8 & 15,56 & 0,65 & 0,13 & 0,65 & 44,44 & 1,38 & 2,67 \\
\hline Tibouchina candolleana (Mart. ex DC.) Cogn. & 2 & 0,024 & 1 & 2,22 & 0,09 & 0,03 & 0,14 & 5,56 & 0,17 & 0,40 \\
\hline T. sellowiana (Cham.) Cogn. & 1 & 0,005 & 1 & 1,11 & 0,05 & 0,01 & 0,03 & 5,56 & 0,17 & 0,25 \\
\hline T. stenocarpa (DC.) Cogn. & 19 & 0,249 & 3 & 21,11 & 0,88 & 0,28 & 1,40 & 16,67 & 0,52 & 2,80 \\
\hline \multicolumn{11}{|l|}{ MELIACEAE } \\
\hline Cabralea canjerana (Vell.) Mart. & 24 & 0,262 & 8 & 26,67 & 1,12 & 0,29 & 1,47 & 44,44 & 1,38 & 3,96 \\
\hline \multicolumn{11}{|l|}{ MONIMIACEAE } \\
\hline Mollinedia clavigera Tul. & 4 & 0,013 & 3 & 4,44 & 0,19 & 0,01 & 0,07 & 16,67 & 0,52 & 0,78 \\
\hline
\end{tabular}


Tabela 2 (continuação)

\begin{tabular}{|c|c|c|c|c|c|c|c|c|c|c|}
\hline Família/Espécie & $\mathrm{Ni}$ & $\begin{array}{l}\mathrm{AB} \\
\left(\mathrm{m}^{2}\right)\end{array}$ & $\mathrm{Np}$ & $\begin{array}{c}\text { DA } \\
\left(\text { ind.ha }^{-1}\right)\end{array}$ & $\begin{array}{l}\mathrm{DR} \\
(\%)\end{array}$ & $\begin{array}{c}\text { DoA } \\
\left(\mathrm{m}^{2} \cdot \mathrm{h}^{-1}\right)\end{array}$ & $\begin{array}{l}\text { DoR } \\
(\%)\end{array}$ & $\begin{array}{l}\text { FA } \\
(\%)\end{array}$ & $\begin{array}{l}\text { FR } \\
(\%)\end{array}$ & $\begin{array}{l}\mathrm{VI} \\
(\%)\end{array}$ \\
\hline \multicolumn{11}{|l|}{ MORACEAE } \\
\hline Ficus enormis (Mart.) Miq. & 3 & 0,016 & 1 & 3,33 & 0,14 & 0,02 & 0,09 & 5,56 & 0,17 & 0,40 \\
\hline F. pertusa L.f. & 10 & 0,093 & 2 & 11,11 & 0,47 & 0,10 & 0,52 & 11,11 & 0,34 & 1,33 \\
\hline \multicolumn{11}{|l|}{ MYRSINACEAE } \\
\hline Myrsine coriacea $(\mathrm{Sw}$.$) Roem. \& Schult.$ & 7 & 0,092 & 3 & 7,78 & 0,33 & 0,10 & 0,51 & 16,67 & 0,52 & 1,36 \\
\hline M. guianensis (Aubl.) Kuntze & 2 & 0,006 & 1 & 2,22 & 0,09 & 0,01 & 0,03 & 5,56 & 0,17 & 0,30 \\
\hline M. umbellata Mart. & 68 & 0,276 & 13 & 75,56 & 3,17 & 0,31 & 1,55 & 72,22 & 2,24 & 6,95 \\
\hline \multicolumn{11}{|l|}{ MYRTACEAE } \\
\hline Calyptranthes clusiifolia O.Berg & 10 & 0,086 & 3 & 11,11 & 0,47 & 0,10 & 0,48 & 16,67 & 0,52 & 1,47 \\
\hline Eugenia acutata Miq & 1 & 0,012 & 1 & 1,11 & 0,05 & 0,01 & 0,07 & 5,56 & 0,17 & 0,28 \\
\hline E. hiemalis Cambess. & 9 & 0,038 & 2 & 10,00 & 0,42 & 0,04 & 0,21 & 11,11 & 0,34 & 0,98 \\
\hline E. involucrata DC. & 28 & 0,075 & 5 & 31,11 & 1,30 & 0,08 & 0,42 & 27,78 & 0,86 & 2,59 \\
\hline Myrcia guianensis (Aubl.) DC. & 3 & 0,007 & 1 & 3,33 & 0,14 & 0,01 & 0,04 & 5,56 & 0,17 & 0,35 \\
\hline M. splendens (Sw.) DC. & 120 & 0,616 & 15 & 133,33 & 5,59 & 0,68 & 3,46 & 83,33 & 2,58 & 11,63 \\
\hline M. tomentosa (Aubl.) DC. & 47 & 0,196 & 9 & 52,22 & 2,19 & 0,22 & 1,10 & 50,00 & 1,55 & 4,84 \\
\hline Pimenta pseudocaryophyllus (Gomes) Landrum & 14 & 0,050 & 7 & 15,56 & 0,65 & 0,06 & 0,28 & 38,89 & 1,20 & 2,14 \\
\hline Psidium guineense $\mathrm{Sw}$. & 1 & 0,002 & 1 & 1,11 & 0,05 & 0,00 & 0,01 & 5,56 & 0,17 & 0,23 \\
\hline P. rufum DC. & 9 & 0,040 & 3 & 10,00 & 0,42 & 0,04 & 0,23 & 16,67 & 0,52 & 1,16 \\
\hline Siphoneugena densiflora O. Berg & 36 & 0,168 & 15 & 40,00 & 1,68 & 0,19 & 0,94 & 83,33 & 2,58 & 5,20 \\
\hline S. widgreniana $\mathrm{O}$. Berg & 1 & 0,005 & 1 & 1,11 & 0,05 & 0,01 & 0,03 & 5,56 & 0,17 & 0,25 \\
\hline \multicolumn{11}{|l|}{ NYCTAGINACEAE } \\
\hline Guapira graciliflora (Schmidt) Lundell & 19 & 0,092 & 5 & 21,11 & 0,88 & 0,10 & 0,52 & 27,78 & 0,86 & 2,26 \\
\hline \multicolumn{11}{|l|}{ PENTAPHYLLACACEAE } \\
\hline Ternstroemia brasiliensis Cambess. & 3 & 0,010 & 2 & 3,33 & 0,14 & 0,01 & 0,05 & 11,11 & 0,34 & 0,54 \\
\hline \multicolumn{11}{|l|}{ PHYLLANTHACEAE } \\
\hline Hieronyma alchorneoides Allemão & 13 & 0,114 & 3 & 14,44 & 0,61 & 0,13 & 0,64 & 16,67 & 0,52 & 1,76 \\
\hline \multicolumn{11}{|l|}{ PROTEACEAE } \\
\hline Roupala montana Aubl. & 12 & 0,165 & 4 & 13,33 & 0,56 & 0,18 & 0,93 & 22,22 & 0,69 & 2,18 \\
\hline \multicolumn{11}{|l|}{ ROSACEAE } \\
\hline Prunus myrtifolia (L.) Urb. & 11 & 0,049 & 7 & 12,22 & 0,51 & 0,05 & 0,27 & 38,89 & 1,20 & 1,99 \\
\hline \multicolumn{11}{|l|}{ RUBIACEAE } \\
\hline Amaioua guianensis Aubl. & 26 & 0,123 & 5 & 28,89 & 1,21 & 0,14 & 0,69 & 27,78 & 0,86 & 2,76 \\
\hline Cordiera elliptica (Cham.) Kuntze & 17 & 0,085 & 5 & 18,89 & 0,79 & 0,09 & 0,48 & 27,78 & 0,86 & 2,13 \\
\hline Coutarea hexandra (Jacq.) K.Schum. & 1 & 0,004 & 1 & 1,11 & 0,05 & 0,00 & 0,02 & 5,56 & 0,17 & 0,24 \\
\hline Faramea nigrescens Mart. & 1 & 0,003 & 1 & 1,11 & 0,05 & 0,00 & 0,01 & 5,56 & 0,17 & 0,23 \\
\hline Guettarda viburnoides Cham. \& Schltdl. & 5 & 0,024 & 2 & 5,56 & 0,23 & 0,03 & 0,13 & 11,11 & 0,34 & 0,71 \\
\hline Psychotria vellosiana Benth. & 29 & 0,088 & 11 & 32,22 & 1,35 & 0,10 & 0,49 & 61,11 & 1,89 & 3,74 \\
\hline Rudgea viburnoides (Cham.) Benth. & 3 & 0,013 & 1 & 3,33 & 0,14 & 0,01 & 0,07 & 5,56 & 0,17 & 0,38 \\
\hline \multicolumn{11}{|l|}{ RUTACEAE } \\
\hline Galipea jasminiflora (A. St.-Hil.) Engl. & 3 & 0,006 & 3 & 3,33 & 0,14 & 0,01 & 0,03 & 16,67 & 0,52 & 0,69 \\
\hline Metrodorea nigra A. St.-Hil. & 10 & 0,047 & 3 & 11,11 & 0,47 & 0,05 & 0,27 & 16,67 & 0,52 & 1,25 \\
\hline \multicolumn{11}{|l|}{ SALICACEAE } \\
\hline Casearia decandra Jacq. & 15 & 0,058 & 4 & 16,67 & 0,70 & 0,06 & 0,32 & 22,22 & 0,69 & 1,71 \\
\hline C. lasiophylla Eichler & 11 & 0,092 & 6 & 12,22 & 0,51 & 0,10 & 0,52 & 33,33 & 1,03 & 2,06 \\
\hline \multicolumn{11}{|l|}{ SALICACEAE } \\
\hline Casearia sylvestris $\mathrm{Sw}$. & 21 & 0,092 & 7 & 23,33 & 0,98 & 0,10 & 0,52 & 38,89 & 1,20 & 2,70 \\
\hline \multicolumn{11}{|l|}{ SAPINDACEAE } \\
\hline Cupania ludowigii Somner \& Ferruci & 2 & 0,004 & 2 & 2,22 & 0,09 & 0,00 & 0,02 & 11,11 & 0,34 & 0,46 \\
\hline C. zanthoxyloides Cambess. & 2 & 0,024 & 1 & 2,22 & 0,09 & 0,03 & 0,13 & 5,56 & 0,17 & 0,40 \\
\hline C. vernalis Cambess. & 18 & 0,076 & 5 & 20,00 & 0,84 & 0,08 & 0,43 & 27,78 & 0,86 & 2,12 \\
\hline Dilodendron bipinnatum Radlk. & 16 & 0,262 & 2 & 17,78 & 0,74 & 0,29 & 1,47 & 11,11 & 0,34 & 2,56 \\
\hline Matayba juglandifolia Radlk. & 21 & 0,072 & 7 & 23,33 & 0,98 & 0,08 & 0,41 & 38,89 & 1,20 & 2,59 \\
\hline \multicolumn{11}{|l|}{ SOLANACEAE } \\
\hline Cestrum laevigatum Schltdl. & 7 & 0,246 & 5 & 7,78 & 0,33 & 0,27 & 1,38 & 27,78 & 0,86 & 2,57 \\
\hline \multicolumn{11}{|l|}{ STYRACACEAE } \\
\hline Styrax latifolius Pohl & 18 & 0,114 & 8 & 20,00 & 0,84 & 0,13 & 0,64 & 44,44 & 1,38 & 2,85 \\
\hline
\end{tabular}


Tabela 2 (continuação)

\begin{tabular}{|c|c|c|c|c|c|c|c|c|c|c|}
\hline Família/Espécie & $\mathrm{Ni}$ & $\begin{array}{l}\mathrm{AB} \\
\left(\mathrm{m}^{2}\right)\end{array}$ & $\mathrm{Np}$ & $\begin{array}{c}\text { DA } \\
\left.\text { (ind.ha' }{ }^{-1}\right)\end{array}$ & $\begin{array}{l}\mathrm{DR} \\
(\%)\end{array}$ & $\begin{array}{c}\text { DoA } \\
\left(\mathrm{m}^{2} \cdot \mathrm{ha}^{-1}\right)\end{array}$ & $\begin{array}{l}\text { DoR } \\
(\%)\end{array}$ & $\begin{array}{l}\text { FA } \\
(\%)\end{array}$ & $\begin{array}{l}\text { FR } \\
(\%)\end{array}$ & $\begin{array}{l}\mathrm{VI} \\
(\%)\end{array}$ \\
\hline \multicolumn{11}{|l|}{ SYMPLOCACEAE } \\
\hline $\begin{array}{l}\text { Symplocos pubescens Klotzsch ex Benth. } \\
\text { THEACEAE }\end{array}$ & 5 & 0,029 & 3 & 5,56 & 0,23 & 0,03 & 0,16 & 16,67 & 0,52 & 0,91 \\
\hline Laplacea fruticosa (Schrad.) Kobuski & 7 & 0,032 & 3 & 7,78 & 0,33 & 0,04 & 0,18 & 16,67 & 0,52 & 1,02 \\
\hline \multicolumn{11}{|l|}{ THYMELAEACEAE } \\
\hline Daphnopsis brasiliensis Mart. \& Zucc. & 6 & 0,028 & 4 & 6,67 & 0,28 & 0,03 & 0,15 & 22,22 & 0,69 & 1,12 \\
\hline D. fasciculata (Meisn.) Nevling & 5 & 0,015 & 4 & 5,56 & 0,23 & 0,02 & 0,08 & 22,22 & 0,69 & 1,00 \\
\hline \multicolumn{11}{|l|}{ URTICACEAE } \\
\hline Cecropia glaziovii Snethl. & 3 & 0,071 & 2 & 3,33 & 0,14 & 0,08 & 0,40 & 11,11 & 0,34 & 0,88 \\
\hline C. pachystachya Trécul & 7 & 0,029 & 5 & 7,78 & 0,33 & 0,03 & 0,16 & 27,78 & 0,86 & 1,35 \\
\hline \multicolumn{11}{|l|}{ VERBENACEAE } \\
\hline $\begin{array}{l}\text { Citharexylum myrianthum Cham. } \\
\text { VOCHYSIACEAE }\end{array}$ & 34 & 0,360 & 8 & 37,78 & 1,58 & 0,40 & 2,02 & 44,44 & 1,38 & 4,98 \\
\hline $\begin{array}{l}\text { Qualea multiflora Mart. } \\
\text { VOCHYSIACEAE }\end{array}$ & 6 & 0,018 & 3 & 6,67 & 0,28 & 0,02 & 0,10 & 16,67 & 0,52 & 0,90 \\
\hline Vochysia magnifica Warm. & 49 & 0,714 & 6 & 54,44 & 2,28 & 0,79 & 4,01 & 33,33 & 1,03 & 7,32 \\
\hline V. tucanorum Mart. & 1 & 0,005 & 1 & 1,11 & 0,05 & 0,01 & 0,03 & 5,56 & 0,17 & 0,25 \\
\hline Total & 2.148 & 17,810 & 18 & 2386,67 & 100 & 19,79 & 100 & 3227,78 & 100 & 300 \\
\hline
\end{tabular}

23 áreas da Tab. 1, estes índices se encontram entre os mais elevados, na $5^{\mathrm{a}}$ e $3^{\mathrm{a}}$ colocação, respectivamente. Como a riqueza de espécies não é das mais altas ( $17^{\text {a }}$ colocação), o valor elevado de $H^{\prime}$ provavelmente se deve mais à elevada equabilidade, ou seja, à inexistência de um pequeno grupo de espécies com forte concentração de abundâncias (dominantes ecológicos). Este padrão foi corroborado por meio da distribuição das dez espécies com maior densidade, que contribuíram com apenas 36,40\% dos indivíduos da amostragem total, sugerindo uma concentração de indivíduos relativamente baixa entre as populações encontradas na área. Este fato pode estar relacionado à amostragem dispersa em uma área relativamente grande, o que diluiria a dominância ecológica, pois esta tende a ser mais pronunciada localmente devido ao típico predomínio em número ou massa de poucas espécies arbóreas em um mesmo hábitat florestal (Richards 1952; Whitmore 1990). A área do fragmento da serra de São José é comparativamente grande e seu relevo é acidentado, o que certamente determina elevada heterogeneidade ambiental e a formação de mosaicos de habitats relacionados à disponibilidade de luz, ao estoque de água, nutrientes e minerais do solo (Garwood 1983; Augspurger 1984; Ashton \& Hall 1992; Burslem 1996; Clark et al. 1998). De forma semelhante, amostragens dispersas em áreas maiores foram relacionadas à menor dominância ecológica nos fragmentos de Bom Sucesso e do Poço Bonito (van den Berg \& Oliveira Filho (2000).

Análises comparativas - Na análise dos padrões florísticos e estruturais, as CCAs apresentaram autovalores muito baixos para os dois primeiros eixos, todos inferiores a 0,3 nas CCAs qualitativas e inferiores a 0,4 nas CCAs quantitativas, o que significa que os gradientes são curtos, ou seja, há grande número de espécies distribuídas ao longo dos gradientes, porém variando sua abundância relativa (ter Braak 1995). Apenas 17,0\% da variação total da matriz florística é puramente ambiental e independente do espaço; 10,5\% é indistintamente espacial e ambiental, ou seja, deve-se à estrutura espacial do próprio ambiente; 9,9\% é puramente espacial e independente do ambiente (Fig. 3A). Em decorrência disso, pouco mais de um terço da variação florística total $(37,3 \%)$ foi explicado por ambiente e espaço em conjunto, restando $62,6 \%$ de variação estocástica ou não explicável pelas variáveis disponíveis. Similarmente, na análise da matriz estrutural, a variação puramente ambiental representa $17,4 \%$, a indistintamente espacial e ambiental 7,6\%; a puramente espacial 10,3\% (Fig. 3B). Desta maneira, ambiente e espaço, em conjunto, responderam por $35,2 \%$ da variação total, restando 64,8\% de variação das espécies, que é estocástica ou não explicável pelas variáveis disponíveis. A expressiva variância remanescente nas duas análises é comum em dados de vegetação e não prejudica a significância das relações espécie-ambiente (ter Braak 1988). De 


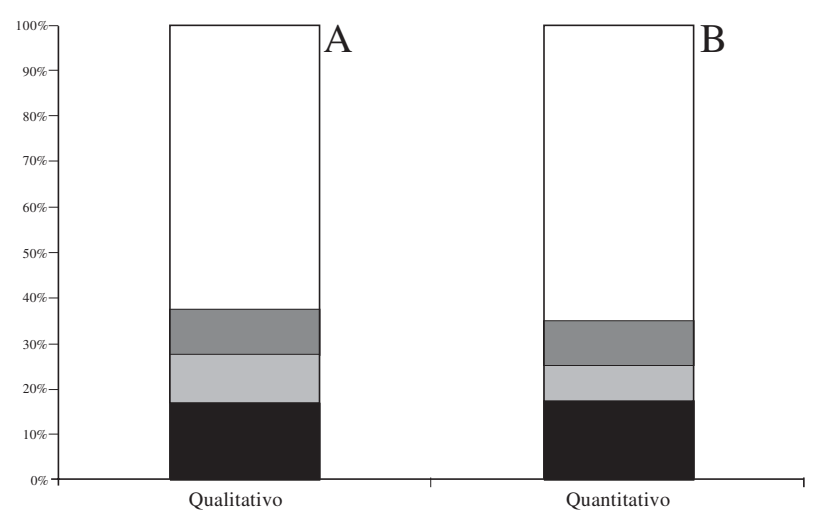

Figura 3. Influência da variação ambiental, espacial e não explicada nas análises de correspondência canônica dos dados florísticos (A) e estruturais (B), dos 24 fragmentos da região do Alto Rio Grande, MG, Brasil, utilizados nas análises comparativas. ( $\square$ = Estocástico; $\square=$ Espaço; $\square=$ Ambiente + Espaço; $\mathbf{\square}=$ Ambiente).

fato, os testes de permutação de Monte Carlo para o conjunto dos eixos de ordenação foram significativos para todas as CCAs $(p<0,05)$ e as correlações espécieambiente foram elevadas $(>0,91)$.

Os diagramas das Fig. 4A-B mostram a ordenação dos dados qualitativos e quantitativos pela CCA1, ou seja, pela análise dos padrões relacionados às variáveis ambientais. Em ambos os diagramas pode ser observada claramente a formação de três grandes grupos distintos. O primeiro grupo, formado por BO1, BO2, BO3 e IB, é composto por áreas sem estação seca pronunciada e situadas em altitudes mais elevadas, sendo todas elas classificadas como Florestas Pluviais Perenifólias Altomontanas sensu Oliveira Filho et al. (2006). O segundo e terceiro grupos são ambos formados por áreas situadas em climas com estação seca pronunciada. $\mathrm{O}$ segundo grupo, que inclui a presente área de estudos, TD, é constituído por duas áreas de Floresta Estacional Semidecídua Altomontana (CR e PB) e duas áreas transicionais, que incluem Floresta Estacional Semidecídua Altomontana e Inferomontana (TD e PI), devido ao fato de serem cortadas pelo limite artificial de corte estabelecido em $1.100 \mathrm{~m}$ de altitude por Oliveira Filho et al. (2006) para separar as duas categorias fisionômicas. O terceiro grupo é formado pelas demais 16 áreas de Floresta Estacional Semidecídua Inferomontana (CM, LA, PN, MD, IT, RM, BS, MI, CP, IU, ML, SE, LU, LV, CQ e IN).

A diferenciação entre os três grupos está provavelmente relacionada, em primeira instância, aos diferentes pisos altitudinais. Desta maneira, pode-se presumir que as áreas do segundo grupo, situadas nas altitudes intermediárias, representariam uma interseção na distribuição de espécies típicas dos dois extremos do gradiente, o que implicaria em maior número de espécies em comum com estes dois grupos do que entre os mesmos. De fato, TD encontra-se em nível altitudinal intermediário entre as formações Inferomontanas e Altomontanas e apresenta padrão

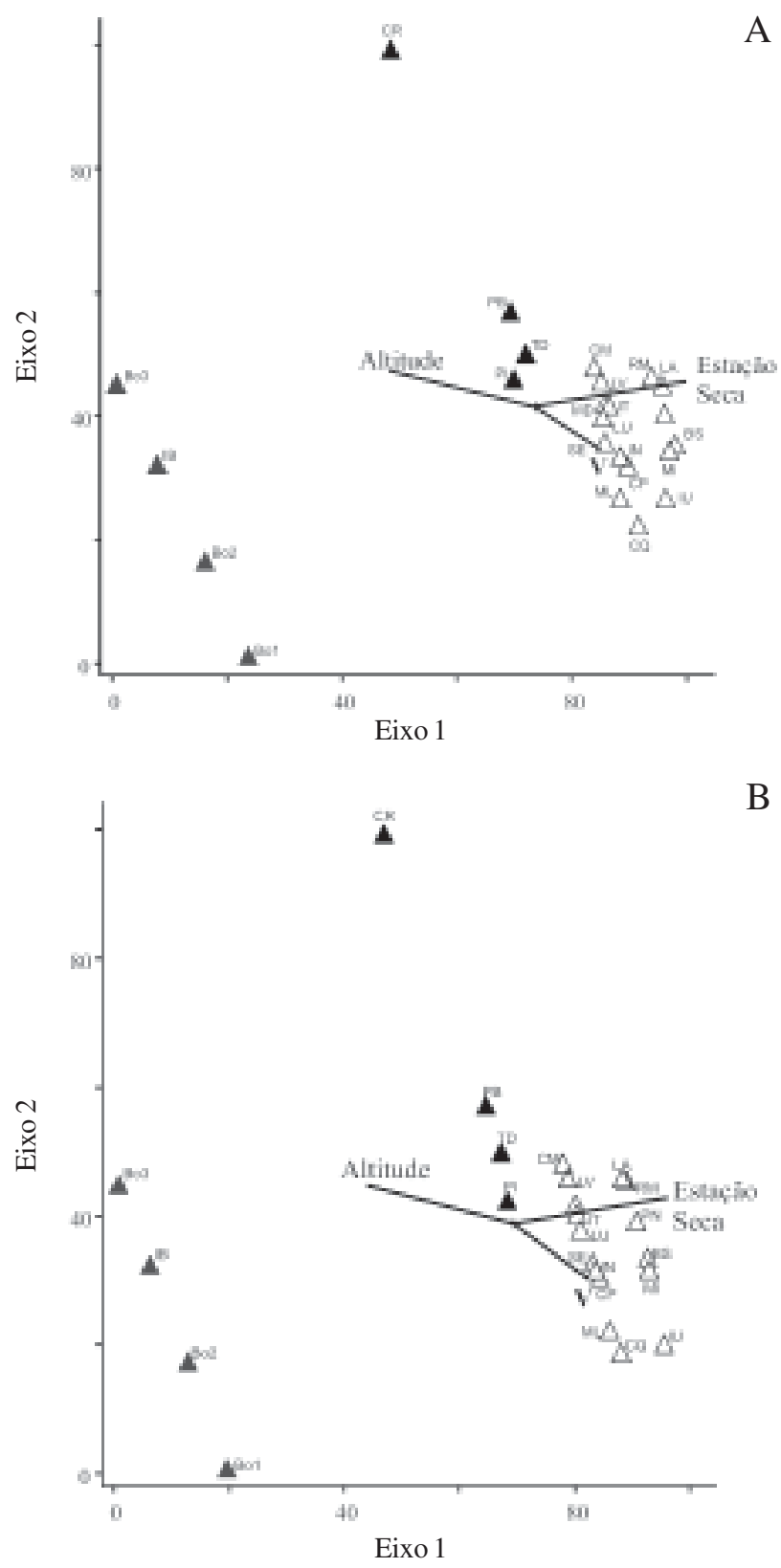

Figura 4. Diagramas de ordenação nos dois primeiros eixos da análise de correspondência canônica (CCA) dos dados florísticos, ou qualitativos (A), e estruturais, ou quantitativos (B), dos 24 fragmentos da região do Alto Rio Grande, MG, utilizados nas análises comparativas. 
florístico nitidamente intermediário entre as duas formações com as quais compartilha um número considerável de espécies: 228 (73,3\%) com ambas, 47 $(15,9 \%)$ exclusivamente com as Inferomontanas e 20 $(6,8 \%)$ exclusivamente com as Altomontanas, restando apenas 16 exclusivas a TD (Fig. 5). Isto significa 94\% de espécies compartilhadas, ao passo que as Florestas Inferomontanas e Altomontanas compartilharam entre si uma proporção bem menor de espécies: 52,2\% do total. Também pode ser constatado que, apesar de TD se encontrar na interseção entre os dois pisos altitudinais, há mais similaridade florística com as Florestas Inferomontanas do que com as Altomontanas, o que é corroborado pela sua posição relativa nos diagramas de ordenação (Fig. 3A) e pelo pequeno número de espécies indicadoras de elevadas altitude entre as relatadas por Oliveira Filho \& Fontes (2000).

Mudanças na composição de espécies e na fisionomia das florestas tropicais ao longo de gradientes altitudinais tem sido bastante documentadas (Velázquez-Rosas et al. 2002; Oliveira Filho et al. 2006). As primeiras comparações entre as florestas do Alto Rio Grande e outras do sudeste do Brasil sugeriram que a altitude e o regime de água dos solos preponderariam na explicação dos padrões de (dis-) similaridade florística (Carvalho et al. 1992; Gavilandes et al. 1992a; b). Contudo, Oliveira Filho et al. (1994a), salientaram que a altitude era o fator mais fortemente relacionado com a similaridade florística entre as

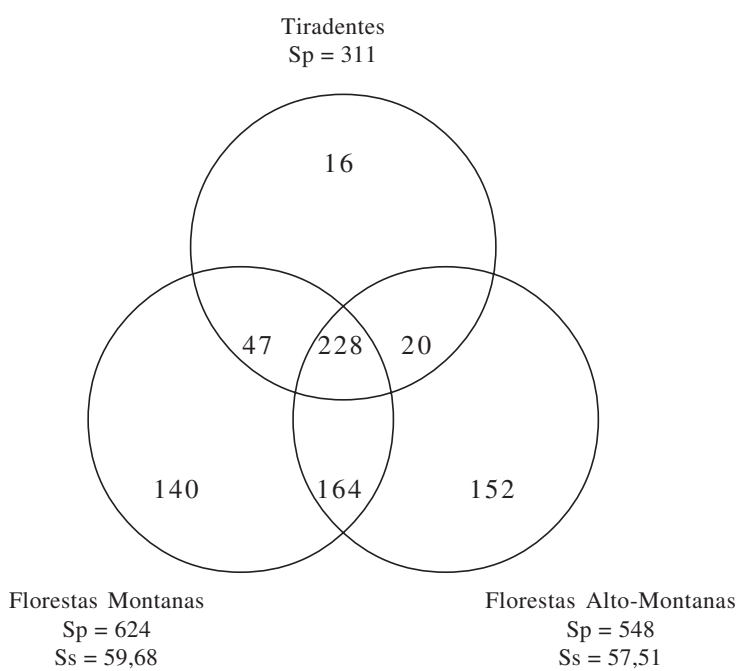

Figura 5. Diagrama de Venn produzido a partir do número de espécies compartilhadas e exclusivas da floresta da serra de São José (TD) e os subconjuntos de Florestas Inferomontanas e Altomontanas dos fragmentos da região do Alto Rio Grande, MG, Brasil, utilizados nas análises comparativas. Onde $\mathrm{Sp}=$ Número de espécies e Ss = Índice de Similaridade de Sørensen. florestas da região, ao agregar um gradiente complexo de variações climáticas. Segundo van den Berg \& Oliveira Filho (2000), diferenças na estacionalidade das chuvas e a influência da proximidade de corpos d'água exerceriam papéis secundários em relação à altitude, mas também importantes. Oliveira Filho \& Fontes (2000), analisando padrões de diferenciação florística entre áreas de Floresta Atlântica no sudeste do Brasil (dentre elas muitas das utilizadas no presente estudo), observaram que a altitude é um fator fundamental de diferenciação tanto de Florestas Semidecíduas como Pluviais. Os autores acrescentaram ainda que a altitude vem provavelmente exercendo uma influência de longo prazo na evolução e especialização da flora do Sudeste do Brasil.

Além do gradiente altitudinal, as CCAs indicaram o déficit hídrico sazonal como um segundo fator com significativa participação na explicação das variações florísticas e estruturais entre as áreas de floresta (Fig. 3A-B), conforme já detectado para florestas estacionais do Sudeste do Brasil por Oliveira Filho et al. (1994a) e van den Berg \& Oliveira Filho (2000). É bem conhecido que a duração da estação seca interfere fortemente no padrão de distribuição de muitas espécies arbóreas do Domínio Atlântico (Oliveira Filho et al. 2006). No entanto, a altitude também interfere muito na disponibilidade de água para as plantas, pois, além do efeito orográfico sobre as chuvas, o déficit hídrico pode ser aliviado a maiores altitudes devido a temperaturas mais baixas e umidade do ar mais elevada (Webster 1995; Whitmore 1990). Desta forma, apesar do inegável papel das temperaturas, ventos e ocorrência de geadas (Oliveira Filho et al. 1994a; Oliveira Filho \& Fontes 2000), o regime de disponibilidade de água pode ser o fator prevalecente na discriminação das florestas do Alto Rio Grande, no gradiente de altitude. Uma evidência adicional a favor da disponibilidade de água é que, entre as Florestas Altomontanas, as Pluviais se diferenciaram fortemente das Semidecíduas nas CCAs e o principal fator envolvido é a inexistência de estação seca nas primeiras.

A fertilidade nutricional do solo, representada pela saturação por bases, ou V, foi apontada pelas CCAs com um terceiro fator significativamente relacionado aos padrões de diferenciação florística e estrutural entre as áreas de floresta (Fig. 3A-B). Em geral, padrões relacionados à fertilidade do solo são mais difíceis de ser detectados em escalas geográficas mais amplas, como a do presente estudo, devido à grande heterogeneidade do substrato em escalas bem menores. 
Inclusive, Pereira et al. (2006), trabalhando com parte das mesmas áreas de floresta do presente estudo, registraram correlações significativas entre a heterogeneidade do substrato e a diversidade de espécies. No presente caso, o gradiente de fertilidade representado por $\mathrm{V}$ crescente mostrou-se em oposição ao gradiente de altitude crescente, sugerindo, novamente, uma amarração com a altitude, como no caso da disponibilidade de água. É comum nas Florestas Altomontanas que os minerais no solo sejam encontrados em camadas finas e cobertos por uma grossa camada de matéria orgânica, sugerindo baixas taxas de decomposição e de mineralização (Edwards \& Grubb 1977; Tanner \& Cuevas 1998). Em altitudes elevadas são comuns os períodos de excesso de água no solo, coincidentes com temperaturas mais baixas que desaceleram a decomposição de matéria orgânica, resultando em solos relativamente mais ricos em baixas altitudes e pobres em elevadas altitudes (VelázquezRosas et al. 2002).

Um fator a ser considerado na forte coesão do grande grupo das Florestas Inferomontanas é que muitas delas (RM, IU, PN, PI, CM, MD, LA) são matas ciliares; logo, é bem provável que sua florística e estrutura sejam semelhantes por abrigarem hábitats semelhantes. No entanto, conforme já salientado por van den Berg \& Oliveira Filho (2000), também deve ser considerado o efeito da mera proximidade geográfica, pois a maioria dessas florestas está concentrada no setor noroeste da região (Fig. 2). É bem sugestivo, portanto, que as variáveis espaciais significativamente relacionadas aos padrões florísticos tenham sido exatamente longitude ${ }^{3}$ e latitude ${ }^{2}$, o que nos remete ao adensamento de áreas de Floresta Inferomontana na direção noroeste, também indicado pelo diagrama das CCAs espaciais (não reproduzidos aqui). De maneira semelhante, as áreas de Florestas Altomontanas concentram-se no setor sudeste da região e são mais distantes geograficamente (Fig. 2), o que reforça o fato de a proximidade espacial exercer, em si mesma, um efeito sobre os padrões florísticos.

Com base nos padrões florísticos e estruturais apresentados entre a Serra de São José e os 24 fragmentos do Alto Rio Grande, conclui-se que a área em questão encontra-se no intermédio das Florestas Inferomontanas e Altomontanas da região, sendo a altitude o fator de maior influência para esta diferenciação. Contudo, também contribuem significativamente para a divergência observada a fertilidade do solo e a duração dos períodos de déficit hídrico, embora estes efeitos não estejam desamarrados do complexo gradiente altitudinal. Este estudo, portanto, agrega valor aos estudos sobre a influência do gradiente altitudinal na composição florística e estrutura da vegetação, que são importantes principalmente quando envolvem uma região tão ampla e com heterogeneidade ambiental tão elevada como a do Alto Rio Grande, pois autoridades ambientais podem se valer muito deste conhecimento ao traçarem políticas de conservação e manejo voltadas para o contexto regional.

\section{Referências bibliográficas}

Angiosperm Phylogeny Group II. 2003. An update of the Angiosperm Phylogeny Group classification for the orders and families of flowering plants: APG II. Botanical Journal of the Linnaean Society 141: 399-436.

Ashton, P.S. \& Hall, P. 1992. Comparisons of structure among mixed dipterocarp forests of north-western Borneo. Journal of Ecology 80: 459-481.

Augspurger C. 1984. Seedling survival of tropical tree species: interactions of dispersal distance, light-gaps, and pathogens. Ecology 65: 1705-1712

Borcard, D.; Legendre, P. \& Drapeau, P. 1992. Partialling out the spatial component of ecological variation. Ecology 73: 1042-1055.

Brower, J.E. \& Zar, J.H. 1984. Field and laboratory methods for general ecology. Dubuque, W.M.C. Brow.

Burslem, D.F.R.P. 1996. Differential responses to nutrients, shade and drought among tree seedlings of lowland tropical forest in Singapore. Pp. 211-244. In: M.D. Swaine (ed.). The ecology of tropical forest tree seedlings. Paris, UNESCO.

Carvalho, D.A.; Oliveira Filho, A.T.; Vilela, E.A. \& Gavilanes, M.L. 1992. Flora arbustivo-arbórea das matas ciliares do alto rio Grande (MG). 1 - mata de Macaia (Bom Sucesso). In Anais do II Congresso Nacional sobre Essências Nativas. Revista do Instituto Florestal 4: 274-282.

Clark, D.B.; Clark, D.A. \& Read, J.M. 1998. Edaphic variation and the mesoscale distribution of tree species in a neotropical rain forest. Journal of Ecology 86: 101-112.

DNMET. 1992. Normais climatológicas (1961-1990). Brasília, Ministério da Agricultura, Departamento Nacional de Meteorologia.

Eiten, G. 1982. Brazilian "Savannas”. Pp. 25-47. In: B.J. Huntley \& B.H. Walker (eds.). Ecology of tropical savannas. Berlin, Verlag.

EMBRAPA 1997. Manual de métodos de análise de solo. Rio de Janeiro, Empresa Brasileira de Pesquisa Agropecuária, Centro Nacional de Pesquisa de Solos.

EMBRAPA 2000. Sistema brasileiro de classificação de solos. $2^{\text {a }}$ ed. Rio de Janeiro, Empresa Brasileira de Pesquisa Agropecuária, Centro Nacional de Pesquisa de Solos.

Edwards, P.J. \& Grubb, P.J. 1977. Studies of mineral cycling in a montane rain forest in New Guinea. 1. The distribution of organic matter in the vegetation and soil. Journal of Ecolgy 65: 943-969. 
Garwood, N.C. 1983. Seed germination in a seasonal tropical forest in Panama: a community study. Ecological Monographs 53: 159-181.

Gavilanes, M.L.; Brandão, M.; Oliveira Filho, A.T.; Almeida, R.J.; Mello, J.M. \& Avezum, F.F. 1992a. Flórula da Reserva Biológica Municipal do Poço Bonito, Lavras, MG. II Formação florestal. Daphne 2: 14-26.

Gavilanes, M.L.; Oliveira Filho, A.T.; Carvalho, D.A. \& Vilela, E.A. 1992b. Flora arbustivo-arbórea das matas ciliares do alto rio Grande (MG). 2 - mata de Madre de Deus de Minas. In Anais do II congresso nacional sobre essências nativas. Revista do Instituto Florestal 4: 253-290.

Gentry, A.H. 1995. Patterns of diversity and floristic composition in neotropical montane forests. Pp. 103-126. In: Biodiversity and conservation of Neotropical montane forests (S.P. Churchill; H. Balslev; E. Forero \& J.L. Luteyn, eds.). New York, The New York Botanical Garden.

Lieberman, D.; Lieberman, M.; Peralta, R. \& Hartshorn, G.S. 1996. Tropical forest structure and composition on a large-scale altitudinal gradient in Costa Rica. Journal of Ecology 84: 137-152.

Lieberman, M.; Lieberman, D.; Peralta, R. \& Hartshorn, G.S. 1995.Canopy closure and distribution of tropical forest tree species at La selva, Costa Rica. Journal of Tropical Ecology 11: 161-178.

Moreno, M.R.; Nascimento, M.T. \& Kurtz, B.C. 2003. Estrutura e composição florística do estrato arbóreo em duas zonas altitudinais na Mata Atlântica de encosta da região do Imbé, RJ. Acta Botanica Brasilica 17: 371-386.

Mueller-Dombois, D. \& Ellemberg, H. 1974. Aims and Methods of Vegetation Ecology. New York, John Wiley \& Sons.

Oliveira Filho, A.T. \& Fontes, M.A.L. 2000. Patterns of floristic differentiation among Atlantic forests in southeastern Brazil, and the influence of climate. Biotropica 31: 71-88.

Oliveira Filho, A.T. \& Machado, J.N.M. 1993. Composição florística de uma floresta semidecídua montana, na Serra de São José, Tiradentes, Minas Gerais. Acta Botanica Brasilica 7: 71-88.

Oliveira Filho, A.T.; Ratter, J.A. \& Shepherd, G.J. 1990. Floristic composition and community structure of a central Brazilian gallery forest. Flora 184: 103-117.

Oliveira Filho, A.T.; Vilela, E.A.; Gavilanes, M.L. \& Carvalho, D.A. 1994a. Comparison of the woody flora and soils of six areas of montane semideciduous forest in Southern Minas Gerais, Brazil. Edinburgh Journal of Botany 51: 355-389.

Oliveira Filho, A.T.; Vilela, E.A.; Carvalho, D.A. \& Gavilanes, M.L. 1994. Effects of soils and topography on the distribution of tree species in a tropical riverine forest in south-eastern Brazil. Journal of Tropical Ecology 10: 483-508.

Oliveira Filho, A.T.; Carvalho, D.; Fontes, M.A.L.; van den Berg, E.; Curi, N. \& Carvalho, W.A.C. 2004. Variações estruturais do compartimento arbóreo de uma floresta semidecídua alto-montana na chapada das Perdizes, Carrancas, MG. Revista Brasileira de Botânica 27: 291-309.
Oliveira Filho, A.T.; Jarenkow, J.A. \& Rodal, M.J.N. 2006. Floristic relationships of seasonally dry forests of eastern South America based on tree species distribution patterns. Pp. 159-192. In: R.T. Pennington; J.A. Ratter \& J.P. Lewis (eds.). Neotropical savannas and dry forests: Plant diversity, biogeography and conservation. The Systematics Association Special volume Series 69. Boca Raton, CRC Press, Taylor and Francis Group.

Pendry, C.A. \& Proctor, J. 1996. The causes of altitudinal zonation of rain forests on Bukit Belalong, Brunei. Journal of Ecology 84: 407-418.

Pereira, I.M.; Oliveira Filho, A.T.; Botelho, S.A.; Carvalho, W.A.C.; Fontes, M.A.L.; Schiavini, I. \& Silva, A.F. 2006. Composição Florística do Compartimento Arbóreo de Cinco Remanescentes Florestais do Maciço do Itatiaia, Minas Gerais e Rio de Janeiro. Rodriguésia 57: 103-126.

Pereira, J.A.A.; Oliveira Filho, A.T. \& Lemos Filho, J.P. 2007. Environmental heterogeneity and disturbance by humans control much of the tree species diversity of Atlantic montane forest fragments in SE Brazil. Biodiversity and Conservation 16: 1761-1784

Proctor, J.; Lee, Y.F.; Langley, A.M.; Munro, W.R.C. \& Nelson, T. 1988. Ecological studies on Gunung Silan, a small ultrabasic mountain in Sabah, Malaysia. I. Environment, forest structure and floristics. Journal of Ecology 76: 320-340.

Rede Nacional de Agrometeorologia. 2004. Normais climatológicas e balanços hídricos (http:// masrv54.agricultura.gov.br/rna (Acesso em: 15/12/2006).

Richards, P.W. 1952. The tropical rain Forest. Cambridge, Cambridge University Press.

Scarano, F.R.; Duarte, H.M.; Franco, A.C.; Mattos, E.A.; Rennenberg, H.; Lüttge, U. \& Gessler, A. 2005. Physiological synecology of tree species in relation to geographic distribution and ecophysiological parameters at the Atlantic forest periphery in Brazil: an overview. Trees-Structure and Function 19: 493-496.

Scarano, F.R. 2002. Structure, function and floristic relationships of plant communities in stressful habitats marginal to the Brazilian Atlantic rain forest. Annals of Botany 90: 517-524.

Scudeller, V.V.; Martins, F.R. \& Shepherd, G.J. 2001. Distribution and abundance of arboreal species in the Atlantic ombrophilous dense forest in Southeastern Brazil. Plant Ecology 152: 185-199.

Tanner, P.M.V. \& Cuevas, E. 1998. Experimental investigation of nutrient limitation of forest growth on wet tropical mountains. Ecology 79: 10-22.

Ter Braak, C.J.F. \& Smilauer, P. 1998. CANOCO - Reference manual and user's guide to Canoco for Windows: software for canonical community ordination (version 4). Ithaca, Microcomputer Power.

Ter Braak, C.J.F. 1987. The analysis of vegetationenvironment relationships by canonical correspondence analysis. Vegetatio 69: 69-77.

Ter Braak, C.J.F. 1988. CANOCO - A FORTRAN program for canonical community ordination by (Partial) (Detrended) (Canonical) correspondence analysis and redundancy analysis, version 2.1. Technical report LWA-88-2, TNO, Wageningen, Intitute of Applied Computer Science. 
Ter Braak, C.J.F. 1995. Ordination. Pp. 91-173. In: R.H.G. Jongman; C.J.F. ter Braak \& O.F.R. van Tongeren (eds.). Data analysis in community and landscape ecology. Cambridge, Cambridge University Press.

Thorntwaite, C.W. 1948. An approach toward a rational classification of climate. Geographical Review 38: 55-94.

van den Berg, E. \& Oliveira Filho, A.T. 2000. Composição florística e estrutura fitossociológica de uma floresta ripária em Itutinga, MG, e comparação com outras áreas. Revista Brasileira de Botânica 23: 231-253.

Velázquez-Rosas, N.; Meave, J. \& Velázquez-Santana, S. 2002. Elevational variation of leaf traits in montane rain forest tree species at la chinantla, southern México. Biotropica 34: 534-546.
Veloso, H.P.; Rangel Filho, A.L.R. \& Lima, J.C.A. 1991. Classificação da vegetação brasileira adaptada a um sistema universal. Rio de Janeiro, Instituto Brasileiro de Geografia e Estatística.

Vilela, E.A. \& Ramalho, M.A.P. 1979. Análise das temperaturas e precipitações pluviométricas de Lavras, Minas Gerais. Ciência e Prática 3: 71-79.

Walter, H. 1985. Vegetation of the earth and ecological systems of the geo-biosphere. $3^{\text {th }}$ ed. Berlin, Springer-Verlag.

Webster, G.L. 1995. The panorama of Neotropical cloud forests. In Biodiversity and conservation of Neotropical montane forests. Pp.53-77. In: S.P. Churchill; H. Balslev; E. Forero \& J.L. Luteyn (eds.). New York, The New York Botanical Garden,

Whitmore, T.C. 1990. An introduction to tropical rain forest. Oxford, Oxford University Press. 